\title{
Community-based intervention programs for adults with addictive behaviors - A Scoping Review Protocol
}

\author{
Ana Paula Enes de Oliveira ${ }^{1}$, Carlos Alberto da Cruz Sequeira ${ }^{2}$, Núria Albacar \\ Riobocó ${ }^{3}$, Francisco Miguel Correia Sampaio ${ }^{4}$ \\ 1PhD student in Nursing and Health at the University of Rovira and Virgilli - Spain \\ 2PhD - Coordinating Professor - Escola Superior de Enfermagem do Porto and \\ CINTESIS Researcher - Portugal \\ $3 \mathrm{PhD}$ - Professor at the University of Rovira and Virgilli - Spain \\ $4 \mathrm{PhD}$ - Associate Professor at the Fernando Pessoa University School of Health and \\ CINTESIS Researcher - Portugal
}

Correspondence - Ana Paula Enes de Oliveira - paulaoliveira@ipportalegre.pt This Scoping Review will be developed under the PhD Program in Nursing and Health the University of Rovira i Virgilli in Tarragona.

\begin{abstract}
Introduction - Addictive behavior can be defined by a person's compulsion to engage in a continuous activity or behavior, despite the negative impact on their ability to remain mentally and/or physically healthy and functional in the home and community. The person may find the behavior rewarding psychologically and be satisfied while involved in the activity, but later he may feel guilt, remorseful or even be overwhelmed by the consequences of this choice on an ongoing basis ${ }^{1}$. Addressing this complexity requires multidisciplinary approaches and a range of responses and devices that, articulately and congruently, act in the various aspects of this phenomenon.

Objective - This review aims to map programs or interventions in a community context with an impact on the cessation / reduction of addictive behaviors in adults, as well as to identify the characteristics of the participants and the contexts of implementation.

Inclusion criteria - Will be considered published and unpublished primary and secondary studies on programs/interventions with an impact on the cessation/reduction of addictive tolls in adults between 18 and 40 years of age in community context, written in Portuguese, Spanish, or English, between 2013 and 2019.

Methods - The Scoping Review will be carried out in accordance with the guidelines of the Joanna Briggs Institute and PRISMA-ScR. From the objective and research questions, the databases and research repositories will be selected, CINAHL Plus with full text (via EBSCO) and MEDLINE with full text (via PubMed), SciELO, Scopus JBI Database of Systematic Reviews, Cochrane Central Register of Controlled Trials, and Cochrane Systematic Reviews and Scientific Repositories; OpenGrey (European repository) and Open Access Scientific Repository of Portugal (Portuguese repository) using all pre-defined Boolean keywords, terms and expressions, to identify studies with inclusion criteria. Duplicate documents will be deleted. The selection of articles will be made by two reviewers independently by reading the title, abstract and full text. The extraction and synthesis of the data will also be performed by two reviewers independently through the analysis grid previously created for this purpose, based on the model of the Joanna Briggs Institute. The data synthesis will be presented in a narrative and table format.
\end{abstract}


Keywords: Adult, intervention program, community, Addictive behaviors, nursing

\section{1 - Introduction}

Addictive behaviors, understood as "addiction processes", are behaviors with impulsive-compulsive characteristics in relation to different activities or behaviors, also involving a potential for pleasure. The continuity and perseverance of this type of behavior, coexisting with other neurobiological, psychological, genetic and environmental factors, may evolve to dependence, which is meant by a set of physiological, cognitive and behavioral phenomena that can develop, for example, after the repeated use of substance. ${ }^{1}$

These addiction processes, with substances such as alcohol, tobacco, licit and illicit drugs and without substance, such as addiction to the internet, sex, shopping, electronic games online and offline, work, eating disorders or physical activity, have presented similarities in the manifestations of physical and psychological dependence, according to recent studies. ${ }^{2}$ These disorders, associated with the disorders and sufferings they cause within the family, at work and social relations, must deserve several interdisciplinary perspectives, so that the conjugated form, one can act minimizing or eliminating these behaviors and their negative consequences.

In Portugal and according to the results of the most recent studies conducted by SICAD (Intervention Service in Addictive Behaviors and Dependencies), some indicators pointed to a worsening of risk or dependence consumption in the general population of 15-74 years, and other worrying negative developments in some population subgroups, such as females and older age groups. ${ }^{3}$

The knowledge acquired within the scope of the various approaches to psychoactive substances must be enhanced, and it is important to extend the knowledge to other addictive behaviors that generate dependencies. Knowledge production thus appears to be a cross-cutting priority, through the development of studies, the training of service professionals to better respond to intervention needs and in the implementation of effective intervention models, extended to other addictive behaviors and dependencies. ${ }^{1}$

The tobacco epidemic is one of the biggest threats to public health, killing more than 8 million people a year worldwide, with 7 million of these deaths being the result of direct tobacco use. Smokers are aware of the dangers of tobacco, most want to quit smoking. Intervention programs and medication may double the possibility of smoking cessation. $^{4}$

In Portugal, despite the relative stability of binge and drunken consumption prevalence in the general population aged 15-74 years, the binge frequency increased and there was a worsening of risk or dependence consumption. On the other hand, this global pattern of evolution covers worrying particular negative evolutions, such as those of the female group and older age groups, and which are sometimes offset by positive developments in men and younger. ${ }^{5}$ Significant regional heterogeneities persist at the level of these consumptions, with alentejo tending to higher values in the various indicators of alcohol consumption. ${ }^{6}$

Since 2012 there has been a worsening prevalence of recent cannabis use. Three fifths of consumers have had daily/almost daily consumption in the last 12 months, noting an aggravating dependence, to point out the worsening in the female group and between the 25-44 years in the Portuguese population in general. Still, Portugal 
continues to emerge below average European values in the prevalence of recent consumption of cannabis, cocaine and ecstasy, with Alentejo being the region with the lowest prevalence of consumption of any drug ${ }^{7}$.

The use of the Internet, is today an indispensable tool for many professionals and students, allowing an easier communication, greater sharing of information and data, and greater speed in access to knowledge. Not least, it is its use as social facilitator, leisure and pleasure. Perhaps by the variety of uses, this virtual reality, has more and more fans and users, which has more and more time in use. In $2019,80.9 \%$ of households in Portugal have internet access at home. $76.2 \%$ of the population living between 16 and 74 years of age uses the Internet, especially students (99.6\%), people who completed secondary education (96.9\%) and higher education $(98.7 \%){ }^{8}$ In recent decades there have been some studies that conceptualize dysfunctional behaviors on the Internet as dependence ${ }^{9}$. The Internet, being a neutral instrument, can have negative or positive effects, depending on how it is used, but it can also help to achieve health gains.

Technological applications (APPs) have been manifesting themselves as a strategy that facilitates interventions and treatments in the health area, in different contexts, and as an increasingly important therapeutic tool for the future. It is essential to improve the training, awareness and attitudes of health professionals who work in the context of addictive behaviors in relation to the use of APPs. ${ }^{10}$

It was described by Berman et al, the evidence found in his research on the feasibility and efficacy of interventions in addictive behaviors, using electronic technologies (DVDs, Web Pages, APPs), presenting an overview of the main components and elements to be considered in the design of interventions that proved effective, also in Community contexts. ${ }^{11}$

Interventions that use planning for decision making in choices can change addictive behavior in any context. Its essence lies in the fact that a biased choice is normative and real people do not choose 'rationally' (...) their 'irrational' deviations show predictable regularities. These interventions aim to promote choices with greater utility and long-term benefits, without restricting access to alternatives. ${ }^{12}$

Concerns about this theme have also been increasing worldwide and by WHO, as addressed at the 2nd global Forum on alcohol, drugs and addictive behaviors (FADAB) promoted by $\mathrm{WHO}$ in 2019 , whose main objective was to improve health actions in these areas, aiming at strengthening partnerships and collaboration between organizations, networks and institutions. Also, in the opinion of its Assistant Director General Dr. Ren Minghui, in this rapidly changing global health market and growing commercialization, strong international collaborations and partnerships are needed to tackle the harmful consumption of alcohol and drugs, as well as universal health coverage for people suffering from disorders due to substance use and addictive behaviors. $^{13}$

The literature has increasingly presented evidence on the effectiveness of interventions in a community context in adults with addictive behaviors, so it is crucial that we know this evidence and map it so that it can be more objectively replicated and adapted to various contexts and participants, obtaining a reduction in addictive behaviors and more gains in health. 
In September and October of 2019, a preliminary exploratory research of Scoping Review or systematic reviews on the theme was conducted in JBI databases of systematic reviews, CINAHL databases, PubMed, EPIP MEDLINE, SciELO, SCOPUS, Cochrane Central Register of Controlled Trials, finding none that corresponded to our object of study. It also allowed to know the state of the art and research needs.

In this sequence, we propose to carry out a Scoping Review, guided by the methodology proposed by the Joanna Briggs Institute ${ }^{14,15}$ with the aim of mapping Programs/Interventions in community context with impact on the cessation/reduction of addictive behaviors in adults, seeking to answer the following questions:

1. What are the characteristics (structure, purpose, duration) of the programs/interventions carried out in the Community context with an impact on the cessation/reduction of addictive behaviors in adults?

2. What are the characteristics of the participants in the programs/interventions with an impact on the cessation/reduction of addictive behaviors?

Evidence-based practice is an expanding field and, with a rapid increase in the availability of primary research, the conduct of reviews as also increased. ${ }^{14}$ Scoping Reviews have an approach designed to synthesize, more effectively, the relevance of evidence, being a type of review whose main objectives are to map the existing evidence underlying a research area and identify gaps in the existing evidence ${ }^{14}$. It does not aim to analyze the methodological quality of the included studies, given that its objective is not to find the best scientific evidence, but its relevance ${ }^{15,14}$. It constitutes an ideal tool to determine the scope and volume of the literature, available studies and the general, broad and detailed overview of information on a given topic ${ }^{16}$. As well as constituting a preliminary work that can lead to a systematic literature review. ${ }^{14}$

To review this theme, we opted for the Scoping Review, as allowing a more comprehensive, complete and repeatable survey of the entire literature, produces more results than a systematic review, due to the greater content of the answers given to broader questions. As an exploratory review, we can include all the results, which will allow us to have a broader and deeper understanding ${ }^{14,15}$ on the characteristics of programs / interventions in a community context for adults with addictive behaviors.

Main elements - The PCC strategy - Population, Concept and Context - will be used:

\section{2 - Inclusion criteria}

Participants - Adults with addictive behaviors.

Studies that integrate adults between 18 and 64 years of age will be considered, with addictive behaviors of any nature, were considered the ages for the concept of adult and middle-aged adult concept were considered to the ages, according to Descriptors in Health Science (DeCS) of $2019^{17}$.

Concept - Programs/interventions for reduction/cessation of addictive behaviors.

Studies that include programs/interventions, promoters of cessation/reduction of addictive behaviors in adults will be considered.

Context - Community

Studies including any Community context, in any country, will be considered as a context of intervention. 
Exclusion factors - Articles older than 6 years old will be excluded, participants with under 19 years of age and over 64 years and interventions in hospital and without the purpose of our objective.

\section{Types of sources}

Any published and unpublished primary studies (original investigations) and secondary studies (systematic literature reviews and narrative reviews), quantitative, qualitative and multi-method / mixed methods studies, as well as observational studies with drawings (descriptive, exploratory and analytical) and experimental (including randomized and non-randomized clinical trials or other quasi-experimental studies) and cross-sectional and longitudinal studies.

The research will be carried out over a period of 20 years (2000 to 2020), considering the most significant period for the appearance of new technologies and digital applications that have provided and conditioned some social changes and that have gradually been reflected in the appearance of addictive behaviors.

The multiple problems associated with CAD, as well as the different aspects and angles through which can be seen, are demonstrative of the need for integrated responses and / or complementary, making its design and operating an example of articulation converging sectoral policies in search of maximization of strategies in interministerial terms, not neglecting the role of civil society ${ }^{1}$.

\section{3 - Methods}

The Scoping Review will methodologically follow the guidelines of the Joanna Briggs Institute as well as the items proposed for the Scoping Reviews reports and extension of Meta-Analyzes ${ }^{14,15}$. The checklist for Scopings Reviews, PRISMA-ScR, developed in accordance with the guidelines published by the EUATOR network for, the, development of guidelines as a matrix for the writing of the report, will be used ${ }^{18,19}$.

\section{1 - Search strategy}

Descriptors in Health Sciences (DeCS) ${ }^{17}$ in Portuguese, Spanish and English considered in the Virtual Library in Health and medical subject headings $(\mathrm{MeSH})^{20}$ will be used: Adulto/Adulto/Adult; Programa de intervenção/Programa de intervención / intervention program; Comportamentos aditivos / Comportamientos aditivos / Addictive behaviors; Comunidade /comunidade /community and boolean expressions ou/o/or and e/y/and.

\section{Will take place in the three recommended steps}

The initial search will be done using the Boolean words and expressions provided by the MEDLINE (with full text) and CINHAL Plus (with full text) databases.

adults or adult

and

"addictive behaviors" or compulsions or addiction

and

"intervention program" or interventions or strategies or "best practices" or "treatment" or therapy or program or management

and

community

From the articles found, an analysis will be made of the text words, contained in the titles and abstracts.

In the second step, the search will be done in all databases and electronic repositories selected, using the keywords, terms and Boolean expressions identified in the previous step (Appendix 1), considering the criteria defined for inclusion of the articles. Duplicate articles will be rejected. 
In the third stage, the lists of bibliographic references of all included articles will be analyzed, in order to identify possible relevant additional studies.

If necessary, contact will be made with the authors of the studies to obtain clarifications or additional information.

\section{4- Information Sources}

The comprehensive search will be conducted in the CINAHL Plus databases with full text (via EBSCO) and MEDLINE with full text (via PubMed), SciELO, Scopus JBI Database of Systematic Reviews, Cochrane Central Register of Controlled Trials, and Cochrane and Systematic Reviews in Scientific Repositories; OpenGrey (European repository) and Scientific Open Access Scientific Repository of Portugal (Portuguese repository).

\section{5 - Studies selection}

The selection process will be done in two phases.

1) Initially, the relevance analysis of the studies will be carried out by two reviewers independently, who will read the title and summary using the inclusion criteria previously defined. All titles suggestive of "interventions or programs" to reduce or cease addictive behavior in adults will be accepted. The full text article will be selected for all articles that meet the inclusion criteria in the review and for those who may raise doubts about its relevance by reading the title and abstract. If the full text of the selected article is not available, it may be requested from its authors. The two reviewers will also read the full text independently to determine its relevance and meet the inclusion criteria previously defined. Only articles that both consider relevant to programs / interventions in a community context for the reduction / cessation of addictive behaviors in adults that meet the inclusion criteria will be included in this Scoping Review.

In case of doubts regarding the interpretation of the documents, the authors will be contacted for clarification or to provide additional information.

2) In the second phase,

The articles in the reference list will be identified by reading the title and later analyzing the abstract and full text. Anyone who meets the inclusion criteria, and is not duplicated, will be included in the review. When the references described do not allow a clear correspondence, the articles will be excluded.

The selection of studies will be illustrated by a PRISMA Flowchart (Appendix 2) Identification (number of articles identified in each database), selection (number of articles selected by title and summary in each database, excluding duplicates), eligibility ( number of articles selected after analyzing the full text) and inclusion (number of articles included in the Scoping Review).

It is intended to use the Mendeley Desktop bibliographic reference organization software, for which the articles obtained in the research will be imported and Microsoft Excel 2016, for its listing and organization.

\section{5 - Data extraction}

The extraction of data should make it possible to identify the general characteristics of the articles and specific aspects of the intervention programs.

The two reviewers will independently extract the data from the articles presented in full text, in order to clarify the details of the population, the concept, context and design of 
the intervention, and thus answer our research questions and achieve the objective proposed. Previously, an instrument (Appendix 3) will be created, based on the PRISMA-ScR Model, proposed by the Joanna Briggs Institute to extract details, characteristics and results of the studies, being aligned with our objective and the research questions. The document can be revised and modified, if necessary, during the data extraction process.

Any differences that may occur during the process, between the two lead reviewers may be resolved using a third reviewer.

\section{6 - Presentation of results}

In this scoping review, the conclusions will be written according to the results that emerge from the analysis of the extracted data, after being summarized and mapped, in alignment with the objective, research questions and scope of the investigation and presented in a table, narrative and descriptive.

Recommendations for future research based on gaps identified from the results will also be presented.

Funding - The authors declare that there is no funding for this project.

Conflicts of interest: The authors declare that there are no conflicts of interest for this project.

Acknowledgements - Nothing to mention

Bibliography:

1 - Serviço de Intervenção nos Comportamentos Aditivos e nas Dependências (2013): Plano Nacional para a Redução dos Comportamentos Aditivos e das Dependências 2013-2020. Serviço de Intervenção nos Comportamentos Aditivos e nas Dependências. [Cited 2019 Jan 19]. Available from: http://www.sicad.pt/BK/Institucional/Coordenacao/Documents/Planos/SICAD Plano N acional Reducao CAD 2013-2020.pdf

2 - Behavioral Addictions - American Addiction Centers Acedido em 03-12-2019:

Disponivel em https://americanaddictioncenters.org/behavioral-addictions

3 - Sumário Executivo Relatórios Anuais 2017. SICAD 2018. [Cited 2019 Nov 02].

Available from:

http://www.sicad.pt/PT/Publicacoes/Paginas/detalhe.aspx?itemld=146\&lista=SICAD P UBLICACOES\&bkUrl=BK/Publicacoes/

4 - Tobacco OMS 2019 [Cited 2019 Nov 10] Available from: https://www.who.int/newsroom/fact-sheets/detail/tobacco

5 - Relatório Anual 2017. A situação do país em matéria de álcool. 2018. SICAD:

Direção de Serviços de monitorização e informação/ Divisao Estatistica e Investigação [Cited 2019 Nov 03] Available from:

http://www.sicad.pt/BK/Publicacoes/Lists/SICAD PUBLICACOES/Attachments/146/Rel atorioAnual $2017 \% 20$ ASituacaoDoPaisEmMateriaDeAlcool PT.pdf

6 - Relatório Anual 2018. A situação do país em matéria de álcool. 2019. SICAD:

Direção de Serviços de monitorização e informação/ Divisao Estatistica e Investigação [Cited 2020 Jan 05]. Available from:

http://www.sicad.pt/PT/Documents/2019/relatorio 2018/RelatorioAnual $2018 \% 20$ ASit uacaoDoPaisEmMateriaDeAlcool.pdf 
7 - Relatório Anual 2018. A situação do país em matéria de drogas e toxicodependências. 2019. SICAD: Direção de Serviços de monitorização e informação/ Divisao Estatistica e Investigação [Cited 2020 Jan 05] Available from: http://www.sicad.pt/PT/Documents/2019/relatorio 2018/Relat\%C3\%B3rioAnual 2018 ASitua\%C3\%A7\%C3\%A3oDoPa\%C3\%ADsEmMat\%C3\%A9riadeDrogasEToxicodepe nd\%C3\%AAncias.pdf

8 -_Instituto Nacional de Estatistica. Destaque informação à Comunicação social Sociedade da informação e do conhecimento Inquérito à Utilização de Tecnologias da Informação e da Comunicação pelas Famílias. 2019. [Cited 2019 Nov 30] Available from:

https://www.ine.pt/xportal/xmain?xpid=INE\&xpgid=ine destaques\&DESTAQUESdest boui $=354447153 \&$ DESTAQUESmodo $=2$

9 - Patrão I. et al. Avaliação e intervenção terapêutica na utilização problemática da internet (UPI), Revista de Psicologia da Criança e do Adolescente, , 2016 7(1-2): p. 221-243. [Cited 2019 Nov 25]; Available from: http://hdl.handle.net/11067/3514 10 - QuaglioG, Pirona A, EspositoG, Karapiperis T, Brand H, Dom G, et al. Knowledge and utilization of technology-based interventions for substance use disorders: an exploratory study among health professionals in the European Union. Drugs: Education, Prevention \& Polily [Internet]. 2019 Oct [cited 2020 jan 19];26(5):437-46. Available from:

http://search.ebscohost.com.sabidi.urv.cat/login.aspx?direct=true\&db=pbh\&AN=13852 4163\&site $=$ ehost-live\&scope $=$ site

11 - Berman A, Hoybye M, Blankers M. Editorial on IJBM Special Issue-E-Health Interventions for Addictive Behaviors. International Journal of Behavioral Medicine [Internet]. 2017 Oct [cited 2020 Jan 19];24(5):641-5. Available from: http://search.ebscohost.com.sabidi.urv.cat/login.aspx?direct=true\&db=pbh\&AN=12525 6875\&site $=$ ehost-live \&scope $=$ site

12 - Tucker JA. Fulfilling the promise of choice architecture interventions for addictive behaviors. Addiction [Internet]. 2018 Jul [cited 2020 Jan 19];113(7):1175-7. Available from:

http://search.ebschohost.com.sabidi.urv.cat/login.aspx?direct=true\&db=pbh\&AN=1300 56250\&site $=$ ehost-live\&scope $=$ site 13 - World Health Organization [homepage in internet]. [Cited 2020 Jan 19]. Available from: https://www.who.int/news-room/events/detail/2019/06/27/default-calendar/whoforum-on-alcohol-drugs-and-addictive-behaviours 14 - Peters MDJ, Godfrey CM, Mclnerney P, Soares CB, Khalil H, Parker D. The Joanna Briggs Institute reviewers' manual 2015: methodology for JBI scoping reviews [Internet]. 2015 ; [Cited 2019 Nov 03] Available from:

http://joannabriggs.org/assets/docs/sumari/Reviewers-Manual Methodology-for-JBIScoping-Reviews 2015 v2.pdf 15. Peters MDJ, Godfrey C, Mclnerney P, Baldini SC, Khalil H, Parker D. Chapter 11: Scoping Reviews. In: Aromataris E, Munn Z (Editors). Joanna Briggs Institute Reviewer's Manual. The Joanna Briggs Institute, 2017. [Cited 2019 Ago 20]. Available from: https://reviewersmanual.joannabriggs.org/

16 - Armstrong R, Hall B, Doyle J, Waters E, 'Scoping the scope' of a cochrane review, Journal of Public Health, Volume 33, Issue 1, March 2011, Pages 147-150, [Cited 2020 Jan 17]. Available from: https://doi.org/10.1093/pubmed/fdr015 
17 - Descritores em ciências da saúde - Biblioteca virtual [Cited 2019 Set 02]

Available from: http://decs.bvs.br/P/decs2019p.htm

18 - Moher D, Liberati A, Tetzlaff J, Altman DG, The PRISMA Group (2009) Preferred Reporting Items for Systematic Reviews and Meta-Analyses: The PRISMA Statement. PLoS Med 6(7): e1000097. [Cited 2019 Nov 30]. Available from https://doi.org/10.1371/journal.pmed.1000097

19 - Tricco AC, Lillie E, Zarin W, et al. PRISMA Extension for Scoping Reviews

(PRISMA-ScR): Checklist and Explanation. Ann Intern Med. 2018;169:467-473. [Epub ahead of print 4 September 2018]. doi: [Cited 2019 Nov 02] Available from:

https://doi.org/10.7326/M18-0850

20 - Medical Subject Headings - [Cited 2019 set 02] Available from

https://www.nlm.nih.gov/mesh/meshhome.html 
Appendix 1: Example of the Research Strategy with descriptors made available by MEDLINE database with full text (access via EBSCOhost Web)

\begin{tabular}{|l|l|l|l|}
\hline Database & Query & Combination of descriptors used & $\begin{array}{l}\text { Number of } \\
\text { articles }\end{array}$ \\
\hline \multirow{4}{*}{ MEDLINE } & S1 & $\begin{array}{l}\text { "addictive behaviors" or addiction or } \\
\text { compulsion }\end{array}$ & \\
\cline { 2 - 4 } & S2 & $\begin{array}{l}\text { Adult or adults } \\
\text { Interventions or strategies or "best practices" } \\
\text { or treatment or therapy or program or } \\
\text { management }\end{array}$ & \\
\cline { 2 - 4 } & S4 & community & \\
\cline { 2 - 4 } & S5 & S1 and S2 and S3 and S4 & \\
\cline { 2 - 4 } & Filters & English, 2000 to 2020, full text & \\
\hline
\end{tabular}

Appendix2 - Diagram of the Scoping Review process, adapted from the PRISMA Declaration of Moher et al (2009)

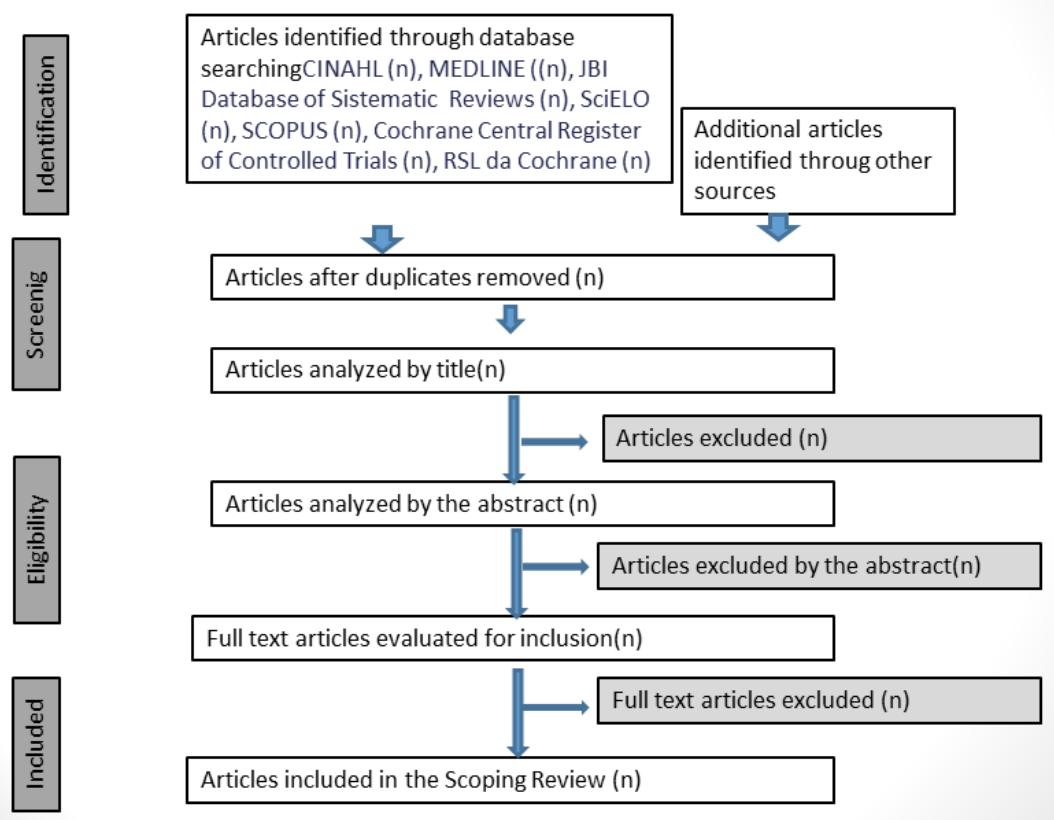

Appendix 3 - Instrument for mapping extracted data

\begin{tabular}{|l|l|l|}
\hline \multicolumn{2}{|c|}{ Data extraction } \\
\hline \multirow{4}{*}{$\begin{array}{c}\text { Article/study } \\
\text { information }\end{array}$} & Title & Indicate full title and subtitles \\
\cline { 2 - 3 } & Publication date & $\begin{array}{l}\text { Indicate to all authors "surname and } \\
\text { abbreviated name" }\end{array}$ \\
\cline { 2 - 3 } & Country of origin & $\begin{array}{l}\text { Refer to where the study was } \\
\text { conducted and published }\end{array}$ \\
\cline { 2 - 3 } & Type of study & $\begin{array}{l}\text { Indicate research method and study } \\
\text { design }\end{array}$ \\
\hline
\end{tabular}




\begin{tabular}{|c|c|c|}
\hline & $\begin{array}{l}\text { Study objectives or } \\
\text { purposes }\end{array}$ & $\begin{array}{l}\text { Explain the reasons for the } \\
\text { development of the study }\end{array}$ \\
\hline \multirow{12}{*}{$\begin{array}{l}\text { Information on } \\
\text { the } \\
\text { Intervention or } \\
\text { intervention } \\
\text { program }\end{array}$} & Name & $\begin{array}{l}\text { Indicate the full name and/or } \\
\text { abbreviation used }\end{array}$ \\
\hline & $\begin{array}{l}\text { Focus/focus of } \\
\text { intervention }\end{array}$ & $\begin{array}{l}\text { Identify the focuses of care and } \\
\text { areas of intervention (clinic, politics, } \\
\text { education, another) }\end{array}$ \\
\hline & Goal & $\begin{array}{l}\text { Clearly identify the purpose of } \\
\text { intervention with influence on the } \\
\text { focus of attention (reduction, } \\
\text { cessation, increase in knowledge, } \\
\text { contribute to improve NHS offers, ...) }\end{array}$ \\
\hline & Participants & $\begin{array}{l}\text { Indicate the number, age, gender, } \\
\text { education by intervention/program, } \\
\text { another relevant }\end{array}$ \\
\hline & Implementation context & $\begin{array}{l}\text { Indicate the contexts or } \\
\text { environments for implementing the } \\
\text { program/intervention }\end{array}$ \\
\hline & Duration & $\begin{array}{l}\text { Indicate the total number and } \\
\text { periodicity of the sessions }\end{array}$ \\
\hline & Methods & $\begin{array}{l}\text { Identify the methods and strategies } \\
\text { used }\end{array}$ \\
\hline & Thematic content & $\begin{array}{l}\text { Refer to which and how the contents } \\
\text { were addressed }\end{array}$ \\
\hline & $\begin{array}{l}\text { Proposed intervention } \\
\text { plan }\end{array}$ & $\begin{array}{l}\text { Indicate details of the intervention } \\
\text { (resources used, planning) }\end{array}$ \\
\hline & Evaluation strategies & $\begin{array}{l}\text { Indicate the methods, instruments } \\
\text { and frequency for monitoring the } \\
\text { effectiveness of the }\end{array}$ \\
\hline & Results & $\begin{array}{l}\text { Identify the results obtained in } \\
\text { participants with the implementation } \\
\text { of the program (reduction, cessation, } \\
\text { another) }\end{array}$ \\
\hline & Professionals involved & $\begin{array}{l}\text { Number of professionals involved, } \\
\text { professional qualifications }\end{array}$ \\
\hline \multicolumn{2}{|c|}{ Key findings related to research issues } & $\begin{array}{l}\text { Address research questions and } \\
\text { identify contributions to improving } \\
\text { health care in general }\end{array}$ \\
\hline \multicolumn{2}{|c|}{ Reference studies } & $\begin{array}{l}\text { Identify studies with greater } \\
\text { relevance or scope of the } \\
\text { intervention }\end{array}$ \\
\hline \multicolumn{2}{|c|}{$\begin{array}{l}\text { Studies of interest for the review obtained in } \\
\text { the list of references }\end{array}$} & $\begin{array}{l}\text { Indicate the bibliographic references } \\
\text { of accepted studies after title } \\
\text { analysis, abstract and full text }\end{array}$ \\
\hline \multicolumn{2}{|l|}{ Gaps found } & $\begin{array}{l}\text { Report difficulties encountered in the } \\
\text { implementation of interventions or } \\
\text { constraints to obtain health gains }\end{array}$ \\
\hline \multicolumn{2}{|l|}{ Other } & \\
\hline
\end{tabular}


Source: JBI Template adaptation study details, characteristics and results extraction instrument ${ }^{15}$ 